\title{
Application of a distributed hydrological model to the design of a road inundation warning system for flash flood prone areas
}

\author{
P.-A. Versini ${ }^{1}$, E. Gaume ${ }^{2}$, and H. Andrieu ${ }^{2}$ \\ ${ }^{1}$ Centre de Recerca Aplicada en Hidrometeorologia UPC, Barcelona, Spain \\ ${ }^{2}$ Laboratoire Central des Ponts et Chaussées, Nantes, France
}

Received: 30 January 2010 - Revised: 31 March 2010 - Accepted: 8 April 2010 - Published: 15 April 2010

\begin{abstract}
This paper presents an initial prototype of a distributed hydrological model used to map possible road inundations in a region frequently exposed to severe flash floods: the Gard region (South of France).

The prototype has been tested in a pseudo real-time mode on five recent flash flood events for which actual road inundations have been inventoried. The results are promising: close to $100 \%$ probability of detection of actual inundations, inundations detected before they were reported by the road management field teams with a false alarm ratios not exceeding $30 \%$.

This specific case study differs from the standard applications of rainfall-runoff models to produce flood forecasts, focussed on a single or a limited number of gauged river cross sections. It illustrates that, despite their lack of accuracy, hydro-meteorological forecasts based on rainfall-runoff models, especially distributed models, contain valuable information for flood event management.

The possible consequences of landslides, debris flows and local erosion processes, sometimes associated with flash floods, were not considered at this stage of development of the prototype. They are limited in the Gard region but should be taken into account in future developments of the approach to implement it efficiently in other areas more exposed to these phenomena such as the Alpine area.
\end{abstract}

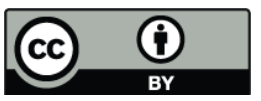

Correspondence to: P.-A. Versini (pierre-antoine.versini@crahi.upc.edu)

\section{Introduction}

Accurate flood forecasts are crucial for efficient flood event management. Until now, hydro-meteorological forecasts have been mainly used to produce early-warnings and flood watches. In Europe there are currently some operational forecasting systems providing mainly early warnings based on real time observations and precipitation forecasts: EFAS, run by the European Joint Research Centre (Thielen et al., 2009), Vigicrues run by SCHAPI in France (Tanguy et al., 2005), and EHIMI run by ACA in Catalonia (Bech et al., 2005) for instance. These existing forecasts are generally limited to gauged cross-sections of large rivers or to specific watersheds with particular assets like hydropower dams, leaving aside large parts of the territory.

In flash-flood prone areas, frequently affected by severe storms with complex spatio-temporal patterns, damage often occurs in the headwater catchments which are most of the time not covered by flood survey networks: see for instance Gaume et al. (2009), Costa and Jarrett (2008) or Borga et al. (2007) among others. When available, flood warnings, often based on the Flash Flood Guidance (FFG) approach (Norbiato et al., 2008; Georgakakos, 2006; Sperfslage et al., 2004; Mogil et al., 1978), help to raise the awareness of rescue services and of the population and to increase their preparedness. But these warnings are not sufficiently accurate in time and space to allow a real-time event management. In an ideal situation, distributed hydrological models, forced by high spatial and temporal resolution rainfall measurements, would be very useful to simulate flood discharges at all the strategic locations on the hydrographic network: towns, structures crossing rivers like bridges or culverts. Such distributed forecasts could for instance provide

Published by Copernicus Publications on behalf of the European Geosciences Union. 
the necessary information for emergency services to identify the areas at risk and to take the appropriate safety and rescue measures: prepositioning of rescue means, stopping traffic on exposed roads, determining safe accesses or evacuation routes.

From a scientific point of view, the development of highly distributed hydrological forecasts raises several difficulties:

1. In many areas, high space and time resolution rainfall estimates are available owing to the developments of raingauge and radar networks. However, Quantitative Precipitation Estimates (QPE) especially radar estimates remain uncertain, particularly when time and space scales suited to flash-flood modelling are considered (Delrieu et al., 2009): sub-hourly time steps and kilometric scale. These rainfall estimation uncertainties are still a major factor limiting the accuracy of rainfallrunoff modelling (Moulin et al., 2009).

2. The implementation of distributed rainfall-runoff models to produce discharge estimates at a high number of watersheds or river cross-sections that are ungauged for a large majority is not straightforward. The Prediction on Ungauged Basins (PUB) is one of the major concerns of the hydrologic community (Sivapalan et al., 2006, 2003). The numerous tests conducted until now show that the performances of most rainfall-runoff models are similar and drop drastically when they are applied without calibration (Andreassian et al, 2006). Is it then reasonable to use rainfall-runoff models to simulate the outflows at ungauged small basins when experience shows that rainfall-runoff models are generally not accurate enough to provide reliable outflows for flood event management at gauged basins?

3. How is it possible to validate the obtained results on most of the points of interest which control ungauged basins: i.e. where no discharge is measured?

Sticking to a purely hydrological approach aimed at providing accurate discharge forecasts, these difficulties can hardly be overcome. But are accurate discharge forecast really necessary? End-users of the hydrological forecasts, especially emergency services, are not interested in discharge values but in anticipating the consequences at the ground of the intense rainfall events. A rough estimation of the possible magnitude of the floods may be sufficient to forecast with some accuracy the induced damages. Moreover, the damages observed in the field may be inventoried and used to evaluate the performances of the hydrological forecasts. Changing the point of view and considering at an early stage of development of forecasting tools the end-users needs, may modify our view on the possible usefulness of distributed hydrological forecasts. This is illustrated here on a specific case study: the development of a first prototype of a road inundation warning system (hereafter RIWS) for the Gard region (South of
France). This case study has been selected for two main reasons: the real-time monitoring of the road network is a major concern for the event management services in this area frequently affected by severe flash floods and where a large proportion of the flood victims are motorists, and the road flooding events are now systematically inventoried providing a large database for the development and the test of the prototype.

The forecasting of possible road flooding events may have some advantages as argued before but poses also some additional problems.

1. The flooding of a river crossing section on a road depends on the magnitude of the flood event but also on its susceptibility to flooding of the road. An efficient warning system has to take into account the variability of this susceptibility to flooding as shown hereafter. One important step of the development of the prototype has consisted of studying a large data set of reported past road inundations to identify the characteristics affecting this susceptibility to flooding. This work is described in a companion paper (Versini et al., 2010).

2. Both pieces of information - susceptibility to flooding and forecasted discharge values - have to be combined to produce flooding risk indices. This will be described hereafter.

This paper presents the components of the proposed road flooding warning system and its first validation results in four test areas on five recent flash floods for which inventories of flooded roads and sometimes time sequences of flooding were available. The paper is organized as follows. Section 2 is devoted to the presentation of the Gard region and of the available data. Section 3 describes the distributed hydrological model and its calibration and validation procedure based on the available gauged discharge series. Section 4 presents how the forecasted discharges and the road susceptibility to flooding are combined to define a road flooding risk level. The forecasted risk levels and the actually observed inundations are compared in Sect. 5 to evaluate the performance of the prototype.

\section{Study area and data set}

\subsection{The Gard region}

Frequently affected by severe flash floods (Gaume et al., 2009; Delrieu et al., 2004b), the Gard region has been chosen as case study. This region has a typical Mediterranean climate characterized by frequent and very heavy storm events occurring especially in Autumn. The 1 in 10 year daily precipitation exceeds $100 \mathrm{~mm}$ on the plateaus (eastern part) and $150 \mathrm{~mm}$ in the mountainous western part of the area 
(CNRS/INPG, 1997). Single storm events often produce locally hundreds of millimeters within a few hours. The monitoring of the road network during flash floods is a major concern for event management services: $40 \%$ of the victims of floods during the last 50 years were motorists trapped in their cars on inundated roads (Antoine, 2001; Ruin et al., 2008), 200 emergency vehicles were seriously damaged or destroyed during the September 2002 extraordinary floods; the local radio "France Bleue Gard Lozère" broadcasts are modified during severe storms to provide information about the road network state.

The inundated road sections are now systematically inventoried during or after every major event by the local services in charge of the maintenance. The data collected during five recent events will serve to evaluate the efficiency of the proposed RIWS prototype. A database of the road inundations reported during the last 40 years, called PICH, has also been built for parts of the region (Lignon, 2004). This information helped understanding what characteristics influence the susceptibility to flooding of river crossing road sections. The analysis of this data set and the resulting road susceptibility to flooding rating method are presented in Versini et al. (2010). The first tests of the RIWS have been conducted on four application zones, chosen for their high density of roads listed in the PICH inventory, i.e. for the potentially high number of inundated roads during severe rainfall events (see Fig. 1). These four zones represent a total area of $350 \mathrm{~km}^{2}$ and a total number of 293 road sections crossing a river: 293 points for which forecasts have to be produced including 41 sections identified in the PICH.

\subsection{The hydrological and meteorological data sets}

The meteorological and hydrological data used in this study have been collected and analysed in the framework of the OHM-CV (Cevennes-Vivarais hydro-meteorological observatory, www.lthe.hmg.ingg.fr/OHM-CV). This observatory is a research initiative aiming at monitoring and understanding intense Mediterranean storms and flash floods (Delrieu et al., 2004a).

\subsubsection{Rainfall intensity data}

35 automatic rain gauges are located within or close to the studied part of the Gard Region (Fig. 1). This rain gauge network has been set up for flood forecasting purposes. In the upper part of the catchments its density is about one gauge per $100 \mathrm{~km}^{2}$. Experience has shown that such a density does not enable accurate estimations of rainfall intensities through spatial interpolations (kriging) at time and space scales suited to flash flood dynamics: sub-hourly time step and kilometric scale (Moulin, 2009). The Gard Region is also covered by two weather radars. However, the radar data available for the studied events were not yet reliable enough to retrieve quantitative precipitation estimates (QPE). Kriging (Yates et

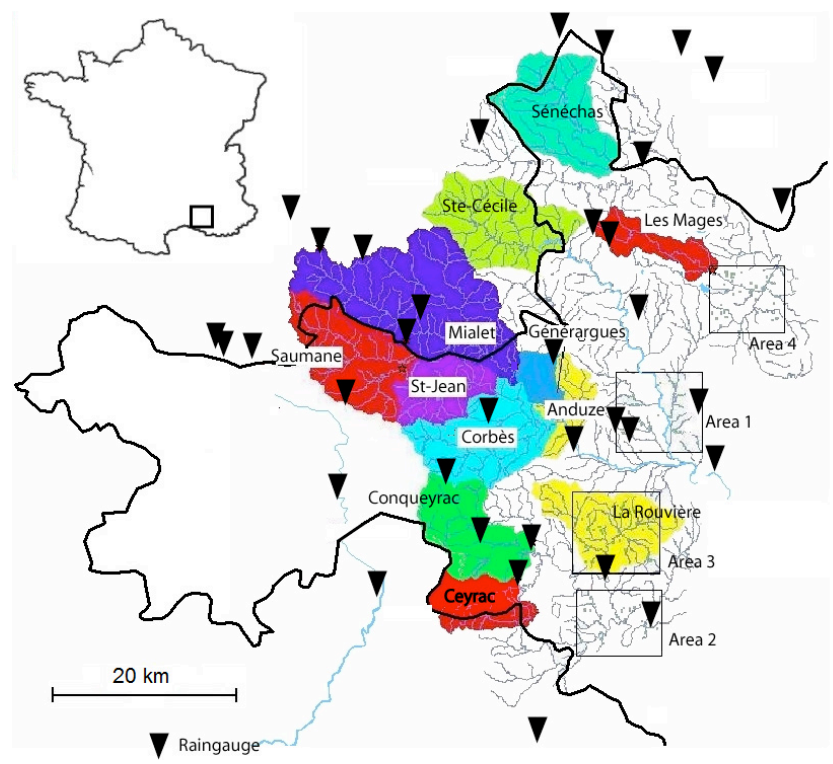

Fig. 1. The study region with location of the raingauges (triangles), of the gauged watersheds (coloured areas) and of the 4 test areas (rectangles).

al., 2008) was used to interpolate the rain gauge measurements and to map rainfall rates at a 15-min time step and a $1 \mathrm{~km}^{2}$ grid covering the study area. The relatively poor accuracy of the rainfall input data, corresponding to the most common situation in operational hydrology, is not favourable for computing accurate flood forecasts but does not prevent from producing valuable distributed inundation warnings as will be illustrated hereafter.

\subsubsection{Discharge data}

The distributed rainfall-runoff model part of the RIWS prototype will be essentially applied on small ungauged watersheds located upstream from road sections crossing rivers. It has been calibrated and validated on the existing stream gauge data: series of hourly discharges over the period 20002005 available for 12 stream gauges. It is worth noting that the gauged watersheds are much larger than most of the watersheds on which the rainfall-runoff model will be applied. The largest considered gauged watershed covers an area of $542 \mathrm{~km}^{2}$ and the smallest has an area of $43 \mathrm{~km}^{2}$, when the average watershed area upstream river crossing road sections in the four test zones is less than $10 \mathrm{~km}^{2}$. Moreover, except one, the gauged watersheds are located upstream of the main river systems and do not cover the test zones (Fig. 1). 


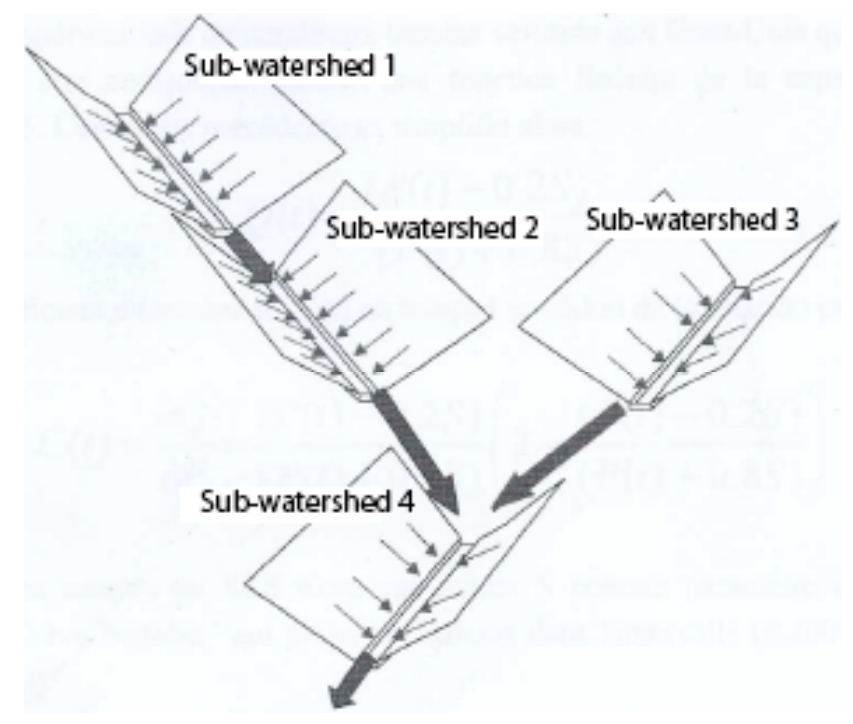

Fig. 2. CINECAR model structure: network of sub-watersheds composed of two slopes and a river reach.

\section{Rainfall-runoff modelling}

\subsection{Choice of the rainfall-runoff model}

A highly distributed rainfall-runoff model is needed to compute simultaneously spatially consistent discharge values at 293 locations of the river network in the 4 test zones. Moreover, the model has to be simple and robust. It has to be regionalized (Blöschl and Sivapalan, 1995) to be applied on ungauged watersheds: the number of its calibration parameters must be limited.

The CINECAR distributed hydrological model (Gaume et al., 2004a) has been therefore selected. It was developed specifically to model flash floods and has been used to simulate the extreme floods that occurred in 2002 in the Gard region (Delrieu et al., 2004b; Gaume et al., 2004b). In this model, watersheds are represented by a network of river reaches having a simple rectangular cross-section, connected to two rectangular slopes as shown in Fig. 2. The US Soil Conservation Service (SCS) Curve Number (CN) model is used to calculate the evolution of the runoff coefficient on each slope during the storm event. The kinematic wave model is used to route the flows on the slopes and through the network of river reaches.

The SCS-CN model was selected among others because of its simplicity. It assumes that the flood flows are essentially composed of surface runoff water or at least fast responding runoff processes. The evolution of the runoff coefficient value during the storm event depends on a single coefficient as follows:

$C(t)=\frac{(P(t)-0.2 S)}{(P(t)+0.8 S)}\left(2-\frac{(P(t)+0.2 S)}{(P(t)+0.8 S)}\right)$ where: $C(t)$ is the runoff coefficient, $P(t)$ is the total rainfall amount in millimetres at time $t, S$ is the retention capacity of the catchment in $\mathrm{mm}$ given by the following equation where the parameter $\mathrm{CN}$ is called "curve number" taking its values between 0 and 100 :

$S=25.4\left(\frac{1000}{\mathrm{CN}}-10\right)$

The kinematic wave model, used to transfer the runoff flows on the slopes and in the river system, appears to be often an accurate approximation of the Saint-Venant shallow water equations governing one-dimensional unsteady free surface flows (Borah et al., 1980). An analytical method is used to solve the kinematic wave differential equations (DaluzVieira, 1983) to avoid the disturbing effect of numerical diffusion on the model results. This transfer function is dominated by two parameters for each river reach: the Strickler's coefficient of roughness and the width of the simplified rectangular cross-section of the river reach. The other coefficients are derived from the digital terrain model: length of the river reaches, average slopes.

A sensitivity analysis revealed that the parameters influencing predominantly the results of the CINECAR model are 1) the widths of the river reaches controlling the propagation velocity of the flood wave and hence the time of concentration of the watersheds and 2) the curve numbers determining the runoff rates. The values of the Strickler's roughness coefficients, of secondary importance, were therefore fixed for the slopes and reaches respectively at 0.1 and 0.05 . These values led to satisfactory results for the simulation of the 2002 flood (Delrieu et al. 2004b; Gaume et al., 2004a, b).

The 293 river crossing road sections in the test zones imposed a division of the area into a large number of small sub-catchments: average area of $2 \mathrm{~km}^{2}$ and largest area lower than $10 \mathrm{~km}^{2}$.

\subsection{Calibration and validation procedures}

The rainfall-runoff model has been adjusted and calibrated based on the measured series available for eight watersheds, covering the variety of encountered landscapes. The four remaining watersheds - representing the same diversity served for the evaluation of the performance of the model applied to area where it has not been calibrated - i.e. to assess its capacity to be extrapolated to ungauged watersheds in the same region.

The widths of the river reaches cannot be determined on the basis of the digital terrain model. They had to be calibrated. For sake of simplicity and based on existing crosssection survey results (Delrieu et al., 2004b), the widths $W_{i}$ have been related to the Strahler order $I$ of the reaches:

$W_{i}=W_{1} \cdot I^{2}$

One single parameter $W_{1}$ has therefore to be calibrated to adjust the transfer function. The same parameter value could be 
Table 1. River widths depending on discharge return period $T$.

\begin{tabular}{ccccc}
\hline$T$ (in years) & Strahler order 1 & Strahler order 2 & Strahler order 3 & Strahler order 4 \\
\hline$T \leq 2$ & $4 \mathrm{~m}$ & $16 \mathrm{~m}$ & $36 \mathrm{~m}$ & $56 \mathrm{~m}$ \\
$2<T \leq 10$ & $8 \mathrm{~m}$ & $32 \mathrm{~m}$ & $72 \mathrm{~m}$ & $112 \mathrm{~m}$ \\
$T>10$ & $12 \mathrm{~m}$ & $48 \mathrm{~m}$ & $108 \mathrm{~m}$ & $168 \mathrm{~m}$ \\
\hline
\end{tabular}

Table 2. Results of the rainfall-runoff model calibration and validation.

\begin{tabular}{cccccc}
\hline Date & $\begin{array}{c}\text { Rainfall } \\
(\mathrm{mm})\end{array}$ & $\begin{array}{c}\mathrm{CN} \\
(\mathrm{LHH} / \mathrm{HHH})\end{array}$ & Width & $\begin{array}{c}\text { Nash calibration } \\
(\mathrm{LHH} / \mathrm{HHH})\end{array}$ & $\begin{array}{c}\text { Nash validation } \\
(\mathrm{LHH} / \mathrm{HHH})\end{array}$ \\
\hline 19 Sep 2000 & 100 & $40-50$ & Set 1 & $0,01 /-1,7$ & $0,38 /-1,2$ \\
27 Sep 2000 & 164 & $40-50$ & Set 2 & $0,30 /-0,99$ & $0,34 / 0,31$ \\
17 Oct 2001 & 193 & $40-50$ & Set 2 & $-0,15 /-0,08$ & $-0,04 /-0,41$ \\
8 Sep 2002 & 335 & $40-50$ & Set 2 & $0,47 / 0,43$ & $0,82 / 0,65$ \\
30 Sep 2003 & 98 & $40-50$ & Set 2 & $0,10 / 0,12$ & $0,47 / 0,66$ \\
15 Nov 2003 & 120 & $50-60$ & Set 3 & $0,08 / 0,27$ & $-0,2 / 0,07$ \\
21 Nov 2003 & 165 & $50-60$ & Set 3 & $0,35 / 0,20$ & $-1,3 /-2,11$ \\
29 Nov 2003 & 230 & $70-80$ & Set 3 & $0,67 / 0,51$ & $-0,27 /-, 041$ \\
25 Oct 2004 & 161 & $40-50$ & Set 2 & $0,35 /-0,11$ & $0,31 / 0,34$ \\
\hline
\end{tabular}

selected for all the watersheds. But due to the simplicity of the transfer function implemented in CINECAR, it appeared necessary to increase the value of $W_{1}$ with the magnitude of the flood. Overbank flow occurs during larger floods, increasing the width of the active river channel and slowing down the flood wave propagation. Three different values of $W_{1}$ have finally been defined depending on the return period of the simulated discharge:

- Moderate discharge (return period $<2$ years), flow confined into the main river channel: $W_{1}=4 \mathrm{~m}$.

- Significant discharge (return period $<10$ years): $W_{1}=8 \mathrm{~m}$.

- Major discharge (return period $>10$ years): $W_{1}=12 \mathrm{~m}$.

The resulting river widths are presented in Table 1.

Concerning the parameter $\mathrm{CN}$, three land cover types (i.e. CNagr for agricultural, CNfor for forest and CNurb for urban areas) and five soil and corresponding bed rock types (i.e. CNall for alluvial soils, CNimp for impervious, CNper for highly pervious, CNmet for metamorphic bedrock covered by shallow soils and CNkar for karstic areas) exist in the region. It appeared nevertheless impossible to calibrate a specific $\mathrm{CN}$ value for each land cover or soil type on the basis of the catchment input-output (i.e. rainfall-discharge) information only. The variability in the land covers of the various catchments as well as in their rainfall-runoff dynamics is not pronounced enough to enable a specific calibration of each $\mathrm{CN}$. This led to the selection of the simplest model with a global average $\mathrm{CN}$ value which appeared as more robust leading to higher extrapolation and validation results. Considering the various sources of uncertainties affecting rainfall-runoff modelling, a range of possible $\mathrm{CN}$ values - the same for all the considered catchments - rather than a single value has been adjusted for each calibration rainfall event. Finally, the variability of the best suited $\mathrm{CN}$ range between rainfall events has been related to variables characterizing the initial moisture condition of the soils and sub-soils of the catchments: date and antecedent rainfall amounts.

Nine storm events with a total average rainfall exceeding $100 \mathrm{~mm}$ on the eight selected gauged calibration watersheds served for the adjustment of the model. For each event, the three sets of width as well as seven $\mathrm{CN}$ values, ranging from 30 to 90 , were tested. Finally, two $\mathrm{CN}$ values were considered, defining a low and a high hydrological response hypothesis (resp. LHH and HHH). An average Nash criterion is calculated to assess the model performance for all the gauged calibration and validation watersheds.

\subsection{Performance of the rainfall-runoff model}

The performances of the model on the calibration and the validation watersheds are shown in Table 2 . They vary from one watershed to the other, and for a given watershed from a storm event to the other. Nevertheless, they are acceptable at the light of the simulation results obtained on comparable case studies for which a strong emphasis was given to model calibration (Borga, 2008). The performance of the model is generally better for the largest rainfall events (see Fig. 3). 

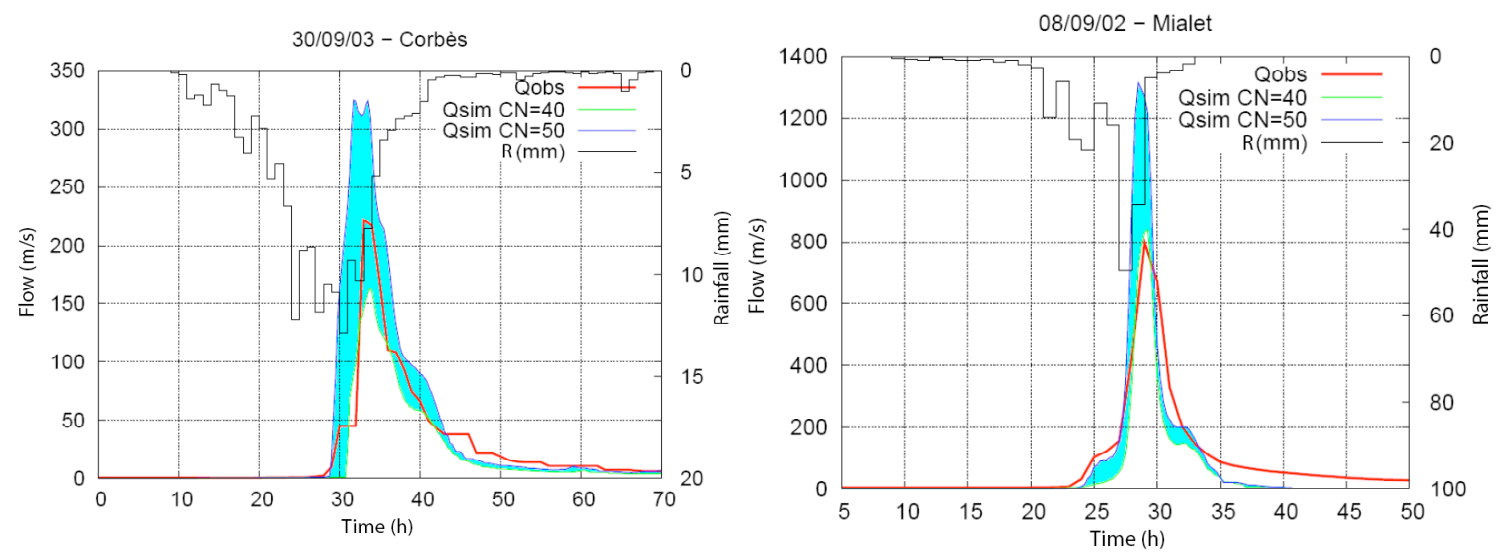

Fig. 3. Comparison between the simulated and measured hydrographs - calibration.
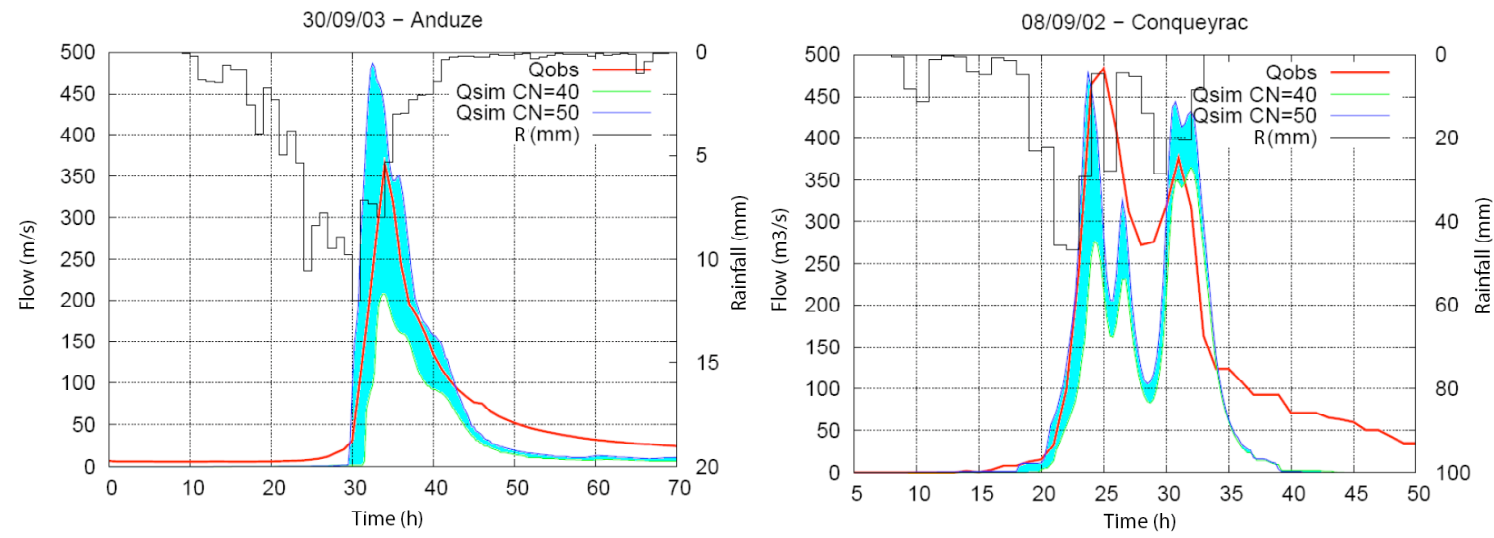

Fig. 4. Comparison between simulated and measured hydrographs - validation.

The hydrological response to smaller rainfall events appears a little more erratic and probably linked to the non-linearity of the rainfall-runoff relationship and to its high sensitivity to slight variations of the initial wetness conditions.

The average values of the Nash criterions may appear modest for many events. Several reasons can be put forward to explain this state of facts. The model parameterization is the same and has not been optimized for each watershed. A highly negative value on one single catchment affects the average Nash value. The estimated rainfall amounts based on spatial interpolation of point rainfall measurements are also a major source of uncertainty despite the relative density of the rain gauge network.

Table 2 shows that the best suited $\mathrm{CN}$ values (LHH and $\mathrm{HHH}$ ) increase during the autumn, which is consistent with a recharge of the soils and the groundwater: from 40 to 50 in September and October, to 50 to 60 in November. The very large value obtained for the event of the 29 of November 2003 is probably linked to the high rainfall amounts which preceded this event. Based on these observations, an empirical relation has been adjusted between $\mathrm{CN}$ and two variables linked to the initial wetness conditions: the amount of precipitation during the last 15 days and the month (see Table 3).
Table 3. Sets of $\mathrm{CN}$ depending on the month and precipitation amount during the 15 preceding days.

\begin{tabular}{ccccc}
\hline Month & September & October & November & December \\
\hline P15days & CN & CN & CN & CN \\
$0-100 \mathrm{~mm}$ & $40 / 50$ & $40 / 50$ & $50 / 60$ & $50 / 60$ \\
$100-200 \mathrm{~mm}$ & $40 / 50$ & $40 / 50$ & $50 / 60$ & $50 / 60$ \\
$200-300 \mathrm{~mm}$ & $50 / 60$ & $50 / 60$ & $60 / 70$ & $60 / 70$ \\
$300-400 \mathrm{~mm}$ & $50 / 60$ & $50 / 60$ & $70 / 80$ & $70 / 80$ \\
$>400 \mathrm{~mm}$ & $60 / 70$ & $60 / 70$ & $80 / 90$ & $80 / 90$ \\
\hline
\end{tabular}

This relation has been used to compute the flood hydrographs for three new events that have served for the testing of the road warning prototype but were not considered in the calibration and validation phase of the CINECAR model: 17 December 2003, 3 November 2004 and 6 September 2005 (see Sect. 5).

The results obtained for the four validation catchments appear similar to the calibration results. Figure 4 shows the results for the events previously illustrated in Fig. 3, and 
Table 2 combines the results of the hydrological validation. The severe storm of 8 September 2002 is well modelled. This is also the case, to a lesser extent, for the events of 27 September 2000, 30 September 2003 and 25 October 2004 events. For the other events, especially for the 29 November 2003 event, the model tends to over-estimate the flood peak discharges on the validation catchments. In some cases (i.e. the 19 September 2000 and 30 September 2003 flood) the validation results are even better than those obtained during calibration. The model and its parameterization seem to be transferable and applicable, with its limits, over the Gard Region.

This calibration and validation procedure may appear quite rough. But it is consistent with the purpose of this study: propose and evaluate the performances of a hydrological model that can be used on ungauged watersheds. As suggested by Stephenson and Freeze (1974): "Finer is not necessary better". The performances of the road inundation warning system (RIWS) will be real test of adequacy of the proposed rainfall-runoff model.

\section{Design of a road inundation warning system}

\subsection{Susceptibility to flooding of the roads}

The main objective of this research is the design a RIWS based on a highly distributed rainfall-runoff model and able to assess a risk of flooding for every intersection between streams and roads every $15 \mathrm{~min}$ during a storm event. This risk level depends on the computed discharge of the considered stream representing the flood hazard, but also on the susceptibility to flooding of the river-crossing structure. This susceptibility can for instance be defined as the return period of inundation of the considered road section which is generally highly correlated, if not equal due to the possible influence of blockages for instance, to the return period of the discharge inducing the inundation.

This return period is seldom known for a stream crossing structure on a road network but thanks to an inventory of past road inundations over the last 40 years in the Gard region (the PICH), an estimate of this return period was available for 167 stream crossing structures. A companion paper (Versini et al., 2010) describes how this data set of 167 known inundation points was analysed to define the susceptibility to flooding of the rest of the crossing structures of the region or at least of the four test zones depending on their geographical characteristics. Four classes of susceptibility to flooding were defined based on these characteristics: 1 . very high, 2. high, 3. medium, 4. low. The highest susceptibility to flooding class contains almost only points where flooding was reported during the last 40 years and the lowest susceptibility class contains none of such points. The flooding return periods are variable within each susceptibility class but

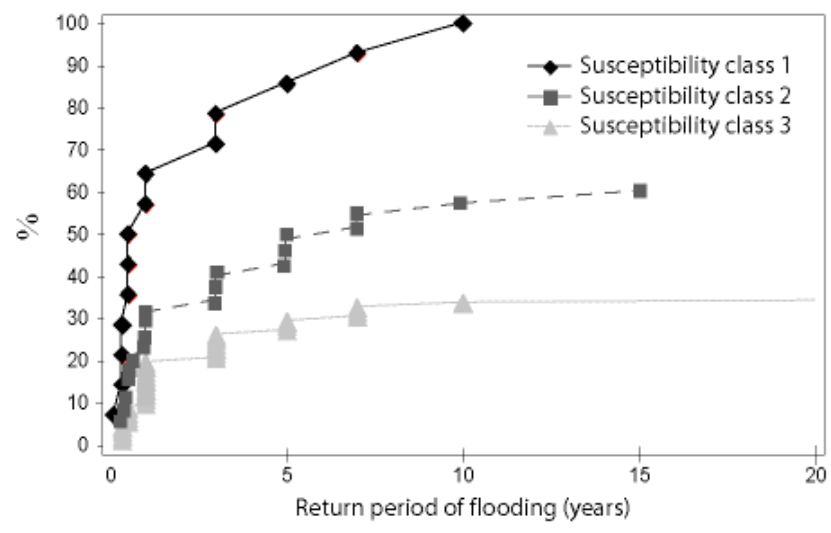

Fig. 5. Distribution of the return period of flooding for each susceptibility class.

the distributions of these return period differ significantly between classes (see Fig. 5).

\subsection{Combination of discharge values and susceptibility to flooding}

The theoretical return period of computed discharges at each time step can be approximated using a regional discharge quantile estimation method, the Crupedix method (Cemagref, 1980) adjusted for France. This formula provides an estimate of the 10-year peak discharge value $\left(Q_{10}\right)$ depending on the area of the watershed.

$Q_{10}=S^{0.8} \cdot\left(\frac{P_{j 10}}{80}\right)^{2} \cdot R \approx 6.8 S^{0.8}$

With $P_{j 10}$ the 10 -year daily rainfall accumulation in $\mathrm{mm}$ (about $160 \mathrm{~mm}$ in the Gard on average) and $R$ a regional coefficient (1.7 for the Gard).

An analysis of the gauged watershed in the Gard indicates that this estimate is consistent with the observed series of discharges. It also reveals that $Q_{10}$ is on average equal to twice the value of the 2-year peak discharge $Q_{2}$ and that the 50 -year peak discharge $Q_{50}$ is twice $Q_{10}$. The Crupedix formula as well as these ratios were used to compute discharge quantiles on the ungauged watersheds.

Given the distribution of flooding return periods in each susceptibility class (Fig. 5) and the return period of the computed discharge, the contingency Table 4 provides the theoretical proportion of inundated road sections in each susceptibility class. It has been considered that no inundation occurs when the return period of the discharge is lower than six months.

Risk levels for the inundation of the road sections are defined based on these theoretical proportions as follows:

- High risk: corresponds to a theoretical proportion of inundated roads exceeding $65 \%$. Inundation of the road is 
Table 4. Proportion of the inundated road section in each susceptibility class depending on the return period of the simulated discharge.

\begin{tabular}{lcccc}
\hline & \multicolumn{4}{c}{ Proportion of class } \\
Susceptibility class & $Q_{2} / 2<Q_{\text {sim }}<Q_{2}$ & $Q_{2}<Q_{\text {sim }}<Q_{10}$ & $Q_{10}<Q_{\text {sim }}<Q_{50}$ & $Q_{\text {sim }}>Q_{50}$ \\
\hline Very high & $65 \%$ & $100 \%$ & $0 \%$ & $0 \%$ \\
High & $33 \%$ & $55 \%$ & $59 \%$ & $100 \%$ \\
Medium & $20 \%$ & $33 \%$ & $34 \%$ & $100 \%$ \\
Low & $0 \%$ & $0 \%$ & $0 \%$ & $20 \%$ \\
\hline
\end{tabular}

Table 5. Summary of the RSWI results when susceptibility classes are considered and when susceptibility classes are not considered (within parentheses).

\begin{tabular}{ccccccccc}
\hline \multirow{2}{*}{ Date } & & & \multicolumn{2}{c}{ POD } & \multicolumn{2}{c}{ FAR } & \multicolumn{2}{c}{ TIM } \\
& Nb of Inundated sections & Rain $(\mathrm{mm})$ & LHH & HHH & LHH & HHH & LHH & HHH \\
\hline 21 Nov 2003 & 6 & 150 & $100 \%$ & $100 \%$ & $4 \%$ & $15 \%$ & - & - \\
& & & $(0 \%)$ & $(83 \%)$ & $(0 \%)$ & $(8 \%)$ & & \\
29 Nov 2003 & 7 & 180 & $100 \%$ & $100 \%$ & $25 \%$ & $30 \%$ & $85 \%$ & $100 \%$ \\
& & & $(43 \%)$ & $(71 \%)$ & $(6 \%)$ & $(13 \%)$ & $(81 \%)$ & $(100 \%)$ \\
17 Dec 2003 & 0 & 60 & - & - & - & - & - & - \\
3 Nov 2004 & 0 & 100 & - & - & - & - & - & - \\
6 Sep 2005 & 56 & 300 & $58 \%$ & $93 \%$ & $19 \%$ & $27 \%$ & $75 \%$ & $80 \%$ \\
& & & $(26 \%)$ & $(74 \%)$ & $(10 \%)$ & $(29 \%)$ & $(63 \%)$ & $(77 \%)$ \\
\hline
\end{tabular}

almost certain. This will affect the very high susceptibility sections as soon as $Q_{\text {sim }}>Q_{2}$.

- Significant risk: when the theoretical proportion of inundations exceeds $33 \%$. It corresponds to the very high susceptibility sections as soon as $Q_{\text {sim }}>Q_{2} / 2$, the high susceptibility sections if $Q_{\operatorname{sim}}>Q_{2}$, and the Moderate susceptibility sections if $Q_{\text {sim }}>Q_{10}$.

- Moderate risk: when the theoretical proportion is higher than $20 \%$. This corresponds to a "vigilance state". Inundation is far from sure but remains possible. We considered that a significant risk has to be affected to the low susceptibility class if $Q_{\text {sim }}>Q_{50}$.

Through their theoretical return periods, the discharges computed every $15 \mathrm{~min}$ at all the intersections between streams and roads can be linked to the susceptibility of these intersections and an inundation risk level can be affected to each intersection point. To assess the usefulness of the road susceptibility rating for the efficiency of the road inundation warning system, simulations were also conducted without considering the susceptibility classes of the road sections. The inundation risk levels are then only based on the return periods of the computed discharges: moderate risk when $Q_{\text {sim }}>Q_{10}$, significant risk when $Q_{\text {sim }}>Q_{50}$.

\section{Test of the proposed road inundation warning system}

\subsection{Evaluation criterions}

The test is based on road inundations reported by local road management services during five recent flash flood events that occurred on 21 November 2003, 29 November 2003, 17 December 2003, 17 November 2004 and 6-9 September 2005. These are the more significant storms in the west part of the Gard region during the period 2003 to 2005. Two of them (21 and 29 November 2003) are included in the data set used for the calibration of the hydrological model. The number of inundated roads in the four test zones as well as the maximum daily point rainfall accumulation over the four test areas estimated through the spatial interpolation of rain gauge measurements are given in Table 5 .

An efficient RIWS should be able to identify a large proportion of the actually observed inundations. The warnings must be delivered before the inundations occur or at least before it is reported and the number of "false warnings" - predicted inundations that are not observed - should be limited. Three criterions were therefore used to evaluate the performance of the proposed RIWS:

- Probability of Detection (POD) calculated as the ratio between the number of inundated sections where a warning has been issued (correct warnings) and the total number of inundated road sections: 


$$
\mathrm{POD}=\frac{\text { Correct Warnings }}{\text { Total number of inundated road sections }}
$$

- False alarm ratio (FAR) calculated as the ratio between the number of non-inundated sections where a warning has been issued (false warnings) and the total number of intersections between roads and streams (possibly inundated points).

$$
\mathrm{FAR}=\frac{\text { False Warnings }}{\text { Total of Intersections }}
$$

- Timing (TIM): proportion of the correct warnings issued before the inundation of the road section is reported. Reported times of inundations were only available for two validation storm events.

$$
\mathrm{TIM}=\frac{\text { Correct Warnings issued in advance }}{\text { Correct Warnings }}
$$

\subsection{Results}

For each studied storm event, the model parameters are chosen according to the values presented in Table 3. Every $15 \mathrm{~min}$, the discharges are computed at all the intersection points between a river and a road in the 4 test zones. These computed discharges are compared to $Q_{2}, Q_{10}$, and $Q_{50}$ specific of each section and the contingency table (Table 4) is used to deduce the inundation risk level depending on the susceptibility class of the road section. The criterions POD and FAR are computed for the whole event taking into account the maximum computed risk levels. The results obtained for the five validation flash flood events are summarized in Table 5.

As for the two first storms (21 and 29 of November 2003), the 13 inundated sections out of the 293 existing intersections are all identified as potentially inundated sections with the low (LHH) or high (HHH) hydrological hypotheses when the susceptibility classes are considered (Table 5). Moreover a majority of these inundated sections are rated with a significant level of risk with the LHH and all these points are rated with significant and high risk level with the HHH, sign that they belong to high susceptibility classes: half of the points rated with a significant or high level of risk have actually been inundated during these two events. A large proportion of the non submerged river crossing sections of the area are not identified as at risk. The rest is generally rated with a moderate inundation risk level, leaving many possibilities for the rescue services to define safe routes, even in these area strongly affected by the intense rainfalls. A 100\% POD is not reached when the susceptibility classes are not considered. Moreover, all the warnings correspond in this case to a moderate risk of flooding: i.e. even if the PODs remain high, the discriminatory power of the RIWS and hence the information content of the forecasts is much lower when the susceptibility of the roads to flooding is not considered. The relatively high POD obtained without taking into account the susceptibility classes along with the low FAR indicate also that the spatial repartition of rainfall plays a dominant role: the theoretical return period of the computed peak discharges at most of the inundated road sections exceeds 10 years. As a partial conclusion, the good performance of the RIWS for these two first test events appears to be the result of the combination of both: 1) a satisfactory forecast of the spatial distribution of discharge values - which was not straightforward according to the roughness of the input data (kriged rainfall fields) and to the limited area of the test zones - about $100 \mathrm{~km}^{2}$ each and 2) the account for the variable susceptibility of roads to flooding. Correct hydrological simulations are not sufficient to provide really valuable road inundation risk forecasts. Information of local susceptibilities to flooding is an important complementary piece of information.

The two next storms have not resulted in inundations in the selected test areas. The warning system does not provide any warning because the simulated discharges did not exceed the lowest defined discharge threshold value $Q_{2} / 2$ at susceptible road sections. This is also a satisfactory result: the rainfallrunoff model does not overestimate the discharges produced by moderate storm events - moderate relatively to the local climate. This stresses the importance of the selection and adjustment of an appropriate rainfall-runoff model for forecasting purposes.

The last flood event of September 2005 is the most important occurred in the test areas over the last ten years. The area has been affected by two successive very intense storm events on 6 and 8 September with point rainfall accumulations reaching $300 \mathrm{~mm}$ on the 6th and exceeding $200 \mathrm{~mm}$ on the 8th. 56 out of the 293 river crossings (i.e. about 20\%) were flooded on the 6 th. The set of inundated roads includes almost all the PICH road sections ( 41 sections in the 4 test areas) but also other sections, the majority of which belonging to the low susceptibility class. A large proportion of these inundated sections were detected by the RIWS: 52 for the High Hydrological Hypothesis, but a moderate risk level is affected to $3 / 5$ of these points. The FAR remains limited even during this extreme event, sign that the rainfall spatial distribution is satisfactorily captured in the kriged rainfall fields and that the rainfall-runoff model is well adjusted: on many of the catchments, the simulated peak discharges did not exceed the theoretical 10-year discharge. But the power of discrimination between probable and less probable inundations is lower than for the two first test storm events. In such a situation where a large number of roads are affected, the performance RIWS is limited by the accuracy of the road susceptibility rating method (see Versini et al., 2010). The performance of the RIWS and especially its discriminatory power - identification of the section at high risk - would be improved if the known flooding frequencies of the road sections, when available, were considered rather than the estimated ones, based on a susceptibility rating method. Let us have a look at some snapshots of the RIWS outcomes to 


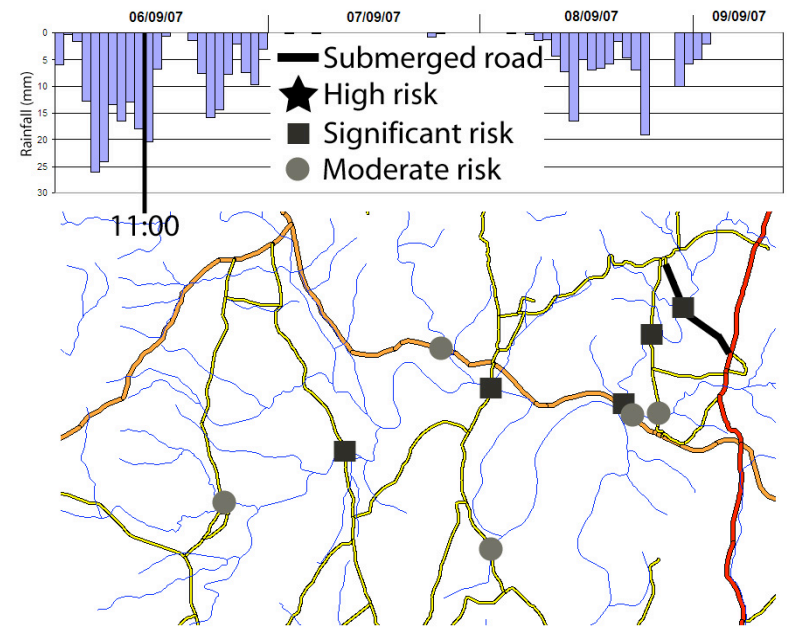

(a)

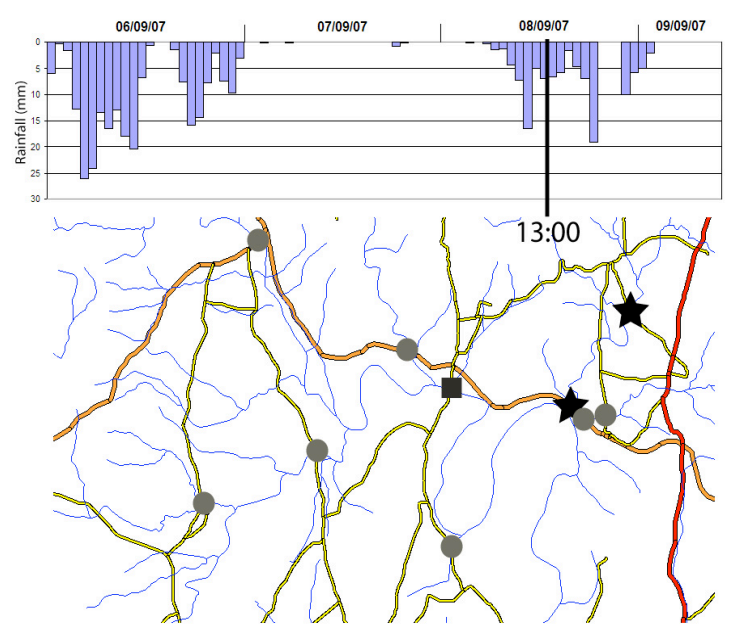

(c)

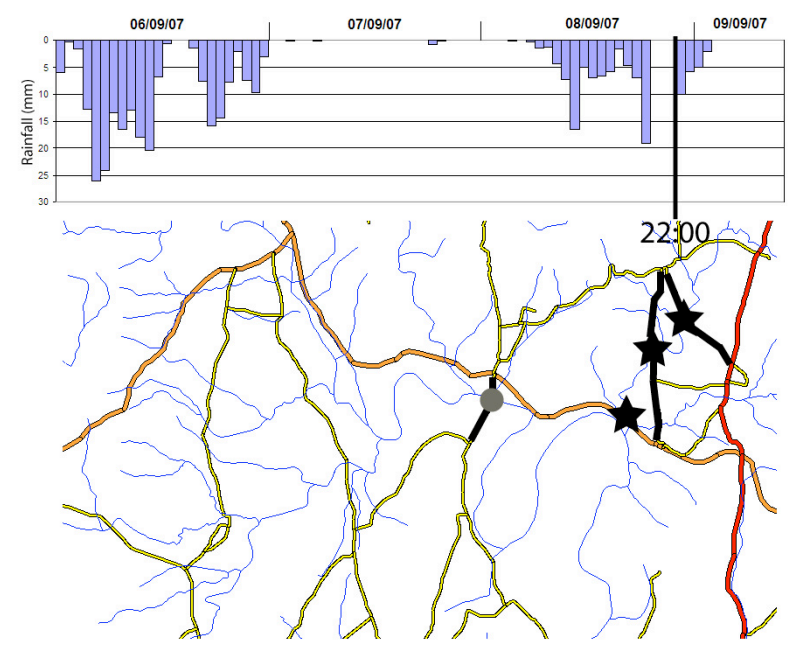

(e)

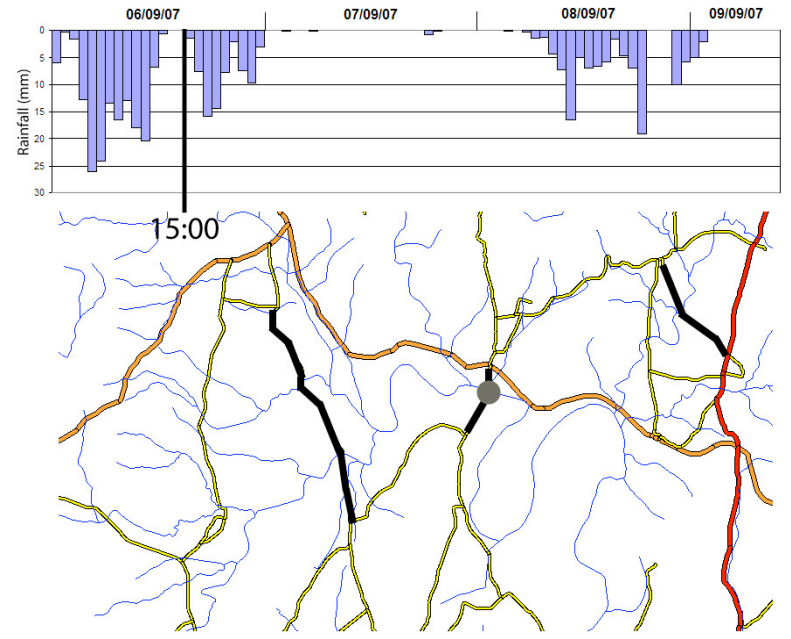

(b)

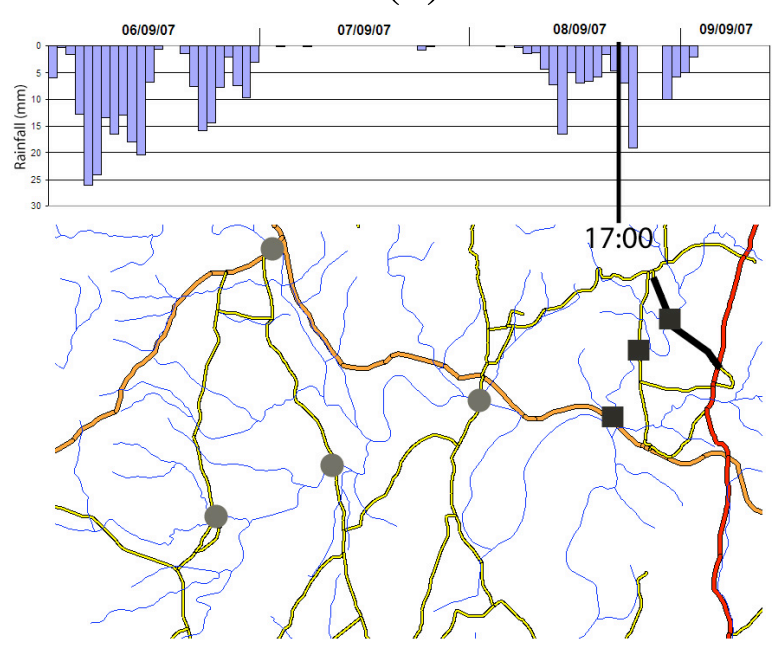

(d)

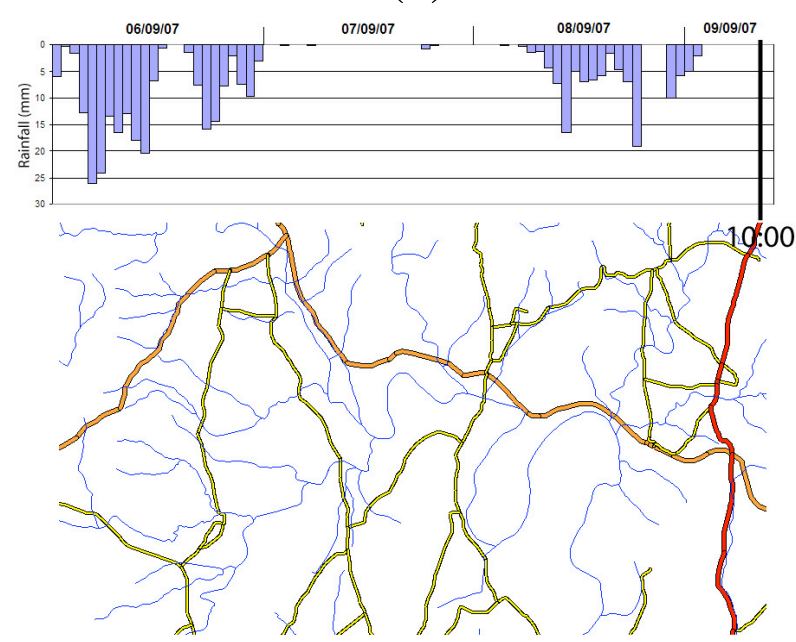

(f)

Fig. 6. Comparison between observed road submersions (bold line) and computed warnings: high risk (stars), significant risk (squares), moderate risk (circles). 
conclude this presentation of results. Beyond the summarized results presented in Table 5, these illustrate how the spatial and temporal pattern and the magnitude of the warnings produced by the RIWS may be helpful for road management and rescue services.

\subsection{Time sequence of the 6-8 September 2005 event}

Figure 6a-f presents some of the maps of the warnings issued at various moments of the flood events on test zone number 2, where the maximum estimated point rainfall amount on 6 September occurred. The reported road inundations are also indicated on this figure. The intense rainfall event began at 04:00 a.m. the 6 September. The RIWS issues the first warnings - moderate risk - at 09:00 when parts of the area had already received more than $100 \mathrm{~mm}$. This late answer of the RIWS seems to be in accordance with the reported inundations. At 11:00, the situation becomes serious according to the RIWS with the multiplication of significant flooding risk levels computed on the road network (Fig. 6a). It is also the moment of the first record of a road inundation. A survey realised at 15:00 by the road management services during a recession period of the floods revealed that two more roads were inundated (Fig. 6b). Both had been already detected as exposed to a significant risk of flooding since 11:00. The inundations can hardly be dated precisely: they are not necessarily immediately detected by the road management services. It is therefore not possible to be sure that the RIWS did really forecast the inundations before they occurred. But at least, the forecasts are generally issued before the inundations are reported. They represent therefore significant additional information for the road management and rescue services. Figure 6a also shows that the whole area is affected by possible inundations except the very western part and this will be confirmed by the inundation reports. Based on such forecasts the traffic from North to South could have been oriented to this less affected area, avoiding the road sections that were actually inundated.

The pattern for the second event on the 8 September is slightly different. The watersheds, already affected by a severe storm on the 6th, reacted more rapidly according to the RIWS, with some high risk levels computed at 13:00 (Fig. 6c). The affected area is also more concentrated in the north-eastern part of the test area. The first inundation, corresponding to probably a well surveyed road, was reported at 17:00 (Fig. 6d). Two other inundations were lately recorded, two hours after the rainfall had ceased (Fig. 6e). These 3 inundations were detected in advance by the RIWS, one of these being a non-PICH point belonging to the medium susceptibility class (i.e. it would not have been detected without the theoretical susceptibility rating method). In this second example, the timing, the spatial repartition and the magnitude of the warning computed by the RIWS appear again correct if not perfect and potentially useful for flood event management services.

\section{Conclusions}

A Road Inundation Warning System for flash flood prone areas has been developed and tested on some sub-areas of the Gard Region. The results obtained are promising. The prototype is able to rate the inundation risk in advance to the field reports on flooding with an acceptable level of accuracy: i.e. relatively high probability of detection (proportion of actually flooded points affected by a significant risk level between 70 and $100 \%$ ), with a reasonable false warning ratio. These preliminary results are not perfect and will remain so. As many forecasting tools, the RIWS prototype should therefore not be considered as a decision support system but rather as a useful source of information, among others, especially field observations, that can help the emergency services during a flood event to improve their decision. The development and the testing of the prototype have revealed that:

1. A detailed inundation susceptibility analysis is required to improve the discriminatory power of the method and the information content of the forecasts. The most susceptible road sections must be identified in advance for the tool to be really informative. In the Gard Region, this susceptibility analysis benefited from the existence of the PICH inventory. A susceptibility rating method has been developed, initially to evaluate the susceptibility to flooding of the road sections outside the area covered by the PICH inventory - for an extrapolation purpose. It has been used here for all the sections as a test, but the RIWS will certainly provide clearer forecasts if the known susceptibilities (empirical return period of inundations) of the road points were directly taken into account when available. The proposed susceptibility rating method may be helpful to develop a similar project in other regions. However, it cannot be directly extrapolated without further tests and adjustments. A road inundation risk computation tool must rely on some information concerning the road network susceptibility to flooding that is partly site specific.

2. The key part of the RIWS is the distributed hydrological model. The spatio-temporal distribution of the rainfall has a major influence on the road network state and the hydrological model must be able to take it into account. The obtained results clearly showed that the hydrological model delivered valuable information for end-users despite its very modest results in terms of ability to accurately simulate the outflows. This conclusion is of key importance as far as the practical usefulness of hydrological models is concerned. The prototype RIWS demonstrated that highly accurate discharge forecasts often the objective of the hydrologists - are not absolutely necessary for event management decisions and that rough estimates of the possible magnitude of the discharges may be sufficient for some issues. Provided that they are thoroughly tested and adjusted to the local 
specificities of the rainfall-runoff relation, the existing models are already able to produce such forecasts of discharge magnitudes as illustrated herein.

This work should be considered as a first example demonstrating that it is technically possible to provide distributed warnings for a high number of ungauged locations in a region - the Gard region counts more than four thousand crossings between rivers and roads - and that these warnings could prove useful despite the uncertainties linked to measured rainfalls and the limits of the hydrological models. Many alternatives to the various choices made herein can be proposed and tested: 1) use of weather radar QPE spatially more accurate but possibly locally biased rather than kriged rainfall fields, 2) test of other rainfall-runoff models and refinements of their calibration, 3) improvement of the susceptibility rating method and extension of its validation, 4) test of other coupling approaches between the computed discharges and the susceptibility of the roads, 5) adapt the model to run it in a forecasting mode rather than in a simulation mode to increase the forecasting lead time by the response time of the watersheds (i.e. between $15 \mathrm{~min}$ and a few hours depending on the area of the watersheds). The next step of the validation of the RIWS will also consist in confronting potential end-users with its outputs.

Finally, these first results open new perspectives for the development of flash flood forecasting tools. Other applications could be suggested, especially applications which would build on databases on local vulnerabilities (dam dimensioning information, data on embankment dimensions and state, hazard and risk maps elaborated for towns): determination of dam or embankment breach or overtopping risk, rating of possible damage magnitude in towns but also identification of debris flow or landslide hazard, particularly important in the case of alpine headwater catchments.

Acknowledgements. This work has been supported by the European Community's Sixth Framework Programme through the grant to the budget of the Integrated Project FLOODsite, Contract GOCE-CT-2004-505420.The authors would like to thank the IGN (Institut Géographique National) institute for providing GIS data. We would also like to thank the INPG of Grenoble and the OHMCV (Cevennes-Vivarais Hydro-Meteorological Observatory) and especially Guy Delrieu, Laurent Bonnifait and Brice Boudevillain for providing historical meteorological data on the Gard region and the staff of the Direction Départementale de l'Equipement du Gard for its cooperation.

Edited by: A. Günther

Reviewed by: S. Fuchs and another anonymous referee

\section{References}

Andréassian, V., Hall, A., Chahinian, N., and Schaake, J.: Large Sample Basin Experiments for Hydrological Model Parameterization: Results of the Model Parameter Experiment - MOPEX, IAHS Publication, 307, 2006.
Antoine, J.-M., Desailly, B., and Gazelle, F.: Les crues meurtrières, du Roussillon aux Cévennes, Annales de Géographie, 110(622), 597-623, 2001.

Bech, J., Rigo, T., Pineda, N., Segalà, S., Vilaclara, E., SànchezDiezma, R., Sempere-Torres, D., and Velasco, E.: Implementation of the EHIMI software package in the weather radar operational chain of the catalan meteorological service, in: Proceedings of 32nd Conference on Radar Meteorology, AlbuquerqueEUA, AMS, P13R.3, 2005.

Blöschl, G. and Sivapalan, M.: Scale issues in hydrological modelling - a review, Hydrol. Processes, 9, 251-290, 1995.

Borah, D. K., Prasad, S. N., and Alonso, C. V.: Kinematic wave routing incorporating shock fitting, Water Resour. Res., 16(3), 529-541, 1980.

Borga, M.: Realtime guidance for flash flood risk management, FLOODsite research project report T16-08-02, 2008.

Borga, M., Boscolo, P., Zanon, F., and Sangati, M.: Hydrometeorological analysis of the August 29, 2003 flash flood in the eastern Italian Alps, J. Hydrometeorol., 8(5), 1049-1067, 2007.

Cemagref: Synthèse nationale sur les crues des petits bassins versants: Méthode SOCOSE et CRUPEDIX, Technical report, 1980.

CNRS/INPG: Atlas expérimental des risques de pluies intenses, région Cévennes-Vivarais, Technical report. CNRS, Laboratoire d'étude des transferts en hydrologie et Environnement, Grenoble, France, 1997.

Costa, J. E. and Jarrett, R. D.: An evaluation of selected extraordinary floods in the United States reported by the US, Geological Survey and implications for future advancement of flood science, USGS, Scientific investigations, Report 2008-5160, Reston, Virginia, 2008.

Daluz-Vieira, J. H.: Conditions governing the use of approximations for the Saint-Venant equations for shallow surface water flow, J. Hydrol., 60, 43-58, 1983.

Delrieu, G., Braud, I., Berne, A., Borga, M., Boudevillain, B., Fabry, F., Freer, J., Gaume, E., Nakakita, E., Seed, A., Tabary, P., and Uijlenhoet, R.: Weather radar and hydrology, Advances in Water Resources, 32(7), 969-974, 2009.

Delrieu, G.: L'Observatoire Hydro-météorologique Méditerranéen Cévennes-Vivarais (The Cévennes-Vivarais Mediterranean Hydro-meteorological Observatory), La Houille Blanche, 6-2003, 83-88, 2004a.

Delrieu, G., Ducrocq, V., Gaume, E., Nicol, J., Payrastre, O., Yates, E., Andrieu, H., Ayral, P.-A., Bouvier, C., Creutin, J.-D., Livet, M., Anquetin, S., Lang, M., Neppel, L., Obled, C., Parent-duChatelet, J., Saulnier, G.-M., Walpersdorf, A., and Wobrock, W.: The catastrophic flash-flood event of 8-9 September 2002 in the Gard region, France: a first case study for the Cévennes-Vivarais Mediterranean Hydro-meteorological Observatory, J. Hydrometeorol., 6, 34-52, 2004b.

Gaume, E., Bain, V., Bernardara, P., Newinger, O., Barbuc, M., Bateman, A., Blaskovicova, L., Bloschl, G., Borga, M., Dumitrescu, A., Daliakopoulos, I., Garcia, J., Irimescu, A., Kohnova, S., Koutroulis, A., Marchi, L., Matreata, S., Medina, V., Preciso, E., Sempere-Torres, D., Stancalie, G., Szolgay, J., Tsanis, I., Velasco, D., and Viglione, A.: A compilation of data on European flash floods, J. Hydrol., 367(1-2), 70-78, 2009.

Gaume, E., Livet, M., Desbordes, M., and Villeneuve, J.-P.: Hydrologic analysis of the Aude, France, flash flood 12 and 13 Novem- 
ber 1999, J. Hydrol., 286, 135-154, 2004a.

Gaume, E. and Bouvier, C.: Analyse hydro-pluviométrique des crues du Gard et du Vidourle des 8 et 9 septembre 2002, La Houille Blanche, 6, 99-106, 2004b.

Georgakakos, K. P.: Analytical results for operational flash flood guidance, J. Hydrol., 317(1-2), 81-103, 2006.

Lignon, S.: Mise en place du Plan d'Intervention Crises Hydrologiques (PICH) à la DDE du Gard, Ecole des Mines d'Ales, Université de Montpellier, 67 p., 2004.

Mogil, H. M., Monro, J. C., and Groper, H. S.: NWS's flash flood warning and disaster preparedness programs, B. Am. Meteorol. Soc., 59, 690-699, 1978.

Moulin, L., Gaume, E., and Obled, C.: Uncertainties on mean areal precipitation: assessment and impact on streamflow simulations, Hydrol. Earth Syst. Sci., 13, 99-114, 2009,

http://www.hydrol-earth-syst-sci.net/13/99/2009/.

Norbiato, D., Borga, M., Degli Esposti, S., Gaume, E., and Anquetin, S.: Flash flood warning based on rainfall thresholds and soil moisture conditions: An assessment for gauged and ungauged basins, J. Hydrol., 362, 274-290, 2008.

Ruin, I., Creutin, J.-D., Anquetin, A., and Lutoff, C.: Human exposure to flash floods - Relation between parameters and human vulnerability during a storm of September 2002 in Southern France, J. Hydrol., 361, 199-213, 2008.

Sivapalan, M., Wagener, T., Uhlenbrook, S., Zehe, E., Lakshmi, V., Liang, X., Tachikawa Y., and Kumar, P.: Predictions in Ungauged basins: promises and progress, IAHS Publication 303, 2006.
Sivapalan, M., Takeuchi, K., Franks, S. W., Gupta, V. K., Karambiri, H., Lakshmi, V., Liang, X., McDonnells, J. J., Mendiondo, E. M., O'Connell, P. E., Oki, T., Pomeroy, J. W., Schertzer, D., Uhlenbrook, S., and Zehe, E.: IAHS Decade on Predictions in Ungauged Basins (PUB), 2003-2012: Shaping an exciting future for the hydrological sciences, Hydrol. Sci., 48(6), 857-880, 2003.

Sperfslage, J. A., Georgakakos, K. P., Carpenter, T. M., Shamir, E., Graham, N. E., Alfaro, R., and Soriano, L.: Central America Flash Flood Guidance (CAFFG) User's Guide. HRC Limited Distribution Report No. 21, Hydrologic Research Center, San Diego, CA, 82 p., 2004.

Stephenson, G. R. and Freeze, R. A.: Mathematical simulation of subsurface flow contributions to snowmelt runoff, Water Resour. Res., 10(2), 284-294, 1974.

Tanguy, J. M., Carriere, J. M., le Trionnaire, Y., and Schoen, R.: Reorganisation of flood forecasting in France - Réorganisation de l'annonce des crues en France, La Houille Blanche, 2, 44-48, 2005.

Thielen, J., Bartholmes, J., Ramos, M.-H., and de Roo, A.: The European Flood Alert System - Part 1: Concept and development, Hydrol. Earth Syst. Sci., 13, 125-140, 2009, http://www.hydrol-earth-syst-sci.net/13/125/2009/.

Versini, P.-A., Gaume, E., and Andrieu, H.: Assessment of the susceptibility of roads to flooding based on geographical information - test in a flash flood prone area (the Gard region, France), Nat. Hazards Earth Syst. Sci., 10, 793-803, 2010, http://www.hydrol-earth-syst-sci.net/10/793/2010/.

Yates, E., Anquetin, S., Ducrocq, V., Creutin, J.-D., Ricard, D., and Chancibault, K.: Hydrological validation of the simulated rain fields, Meteorological Applications, 13, 1-20, 2006. 